\title{
Beyond Transcendentalism and Naturalization: A Categorial Framework for the Semiotic Phenomenology
}

\author{
Martina Properzi \\ Department of Philosophy, Pontifical Lateran University of Rome, Rome, Italy \\ Email address: \\ martinaproperzi@alice.it \\ To cite this article: \\ Martina Properzi. Beyond Transcendentalism and Naturalization: A Categorial Framework for the Semiotic Phenomenology. International \\ Journal of Philosophy. Vol. 7, No. 3, 2019, pp. 122-134. doi: 10.11648/j.ijp.20190703.14
}

Received: June 15, 2019; Accepted: August 9, 2019; Published: September 26, 2019

\begin{abstract}
This paper focuses on the topic of intentionality, which is the power of the mind to be directed towards some object or state of affairs. Intentionality structures the (inter) subjective side of experience, traditionally explored by Edmund Husserl's phenomenology. I intend to introduce the basics of a semiotic interpretation of phenomenological intentionality with the undertaking of realistically grounding it, going beyond the alternative approaches of Modern transcendentalism and the contemporary trend to re-orient phenomenology naturalistically excluding the foundational perspective. This is possible in virtue of a relational reading of phenomenological ontology, where the theoretical core is the following: a sign-driven synthesis of the object, occurring within the onto-logical sphere of the signification processes (semeiosis), and hence outside the epistemological sphere of the subjective self-consciousness. Based on a fragmentary suggestion detectable in the early phenomenological work of the German phenomenologist Max Scheler, the proposed interpretation aims at strengthening the traditional (inter) subjective approach of phenomenology to the categorial study with the "in the third person" objective approach distinctive of semiotics, sharing in principle with the former a common pre-logical and hence ante-predicative level of enquiry. Mathematical Category Theory provides a rigorous framework in developing this unification step, because it deals with relational structures (relational categories) underpinning the predicative ones.
\end{abstract}

Keywords: Intentionality, Object, Categories, Formal Ontology, Phenomenological Realism, Semiotic Phenomenology, Dyadic and Triadic Relations, Topos Theory

\section{Introduction}

This paper focuses on the topic of intentionality, which is the power of the mind to be directed towards some object or state of affairs. Intentionality structures the (inter) subjective side of experience, traditionally explored by Edmund Husserl's phenomenology, that is the descriptive and constitutive study of the intentional structures of the mind insofar as they are (self-) consciously experienced by the subject(s) [1,2]. I intend to introduce the basics of a semiotic interpretation of phenomenological intentionality with the undertaking of realistically grounding it, going beyond the alternative approaches of Modern transcendentalism and the contemporary trend to re-orient phenomenology naturalistically excluding the foundational perspective.

According to a transversal understanding of the notion, which is shared by Classical, Modern, and Contemporary philosophies, "transcendental" means the extra-logical foundation of the possibility and knowability of truth [3, 4]. "Naturalization", in the broader sense made clear by J.-M. Roy et al., is the trend to integrate non-mathematized sciences, especially humanities, within an "explanatory framework where every acceptable property is made continuous with the properties admitted by natural sciences" [5]. This leads to the underlying question of the possibility of constructing and/or confirming scientific theories that explain also "phenomenological data", i.e., contents of (self-) conscious lived experiences described by phenomenology. References [6, 7] provide an updated overview of the contemporary attempts to naturalize phenomenology, questioning Husserl's descriptive and transcendental stance. My suggestion will try to implement what was envisaged by eminent scholars [8-10]: namely, the idea that a contemporary "broader conception of phenomenology" relies on the resolution of both methodological and theoretical contrasts between the naturalized and transcendental 
phenomenology, which have been weakening the contribution of the discipline with respect to the contemporary scientific scenario.

In this direction, the so-called semiotic phenomenology could be considered a good candidate. Recent approaches to this perspective are presented in the 2015 Methodo issue edited by A. Bondì and F. La Mantia [11]. However, following a fragmentary suggestion detectable in the early phenomenological work of the German realistic phenomenologist Max Scheler, ${ }^{1}$ my proposal takes a different direction which is compatible with that recently presented by $\mathrm{M}$. Harney $[12,13]$.

\subsection{Unification Strategies: An Open Debate}

At least since the pioneering Varela's paper Neurophenomenology: A Methodological Remedy for the Hard Problem the attention of the scholars was and is still focused on a methodological unification strategy, basically aimed at inserting phenomenological analysis within the research and/or experimental protocols of psychological and cognitive (neuro) sciences [14, 15]. There are three basic suggestions for the implementation of this unification strategy, namely formalized phenomenology, neurophenomenology, and front-loaded phenomenology [89]. In whatever way it may be judged, however, the methodological approach to unification has left open several theoretical questions that essentially deal with the relationship between the transcendental and naturalized level of enquiry within phenomenology.

This core task is clearly seen by De Preester and, above all, by Gallagher, where he asks for a renewal of the transcendental perspective within phenomenology completely developing the "broader conception of phenomenology" abovementioned $[16,8]$. In other terms, what is needed here seems to be a new interpretation of the subject-object intentional correlation that phenomenologists traditionally consider transcendental.

Starting from some historical remarks, it is important to note that already in its early German phase phenomenology was characterized by a vigorous internal meta-theoretical and meta-methodological debate [17]. This notably led to the formation and consolidation of the Munich and Gottingen circles of early realistic phenomenology [18-21]. ${ }^{2}$

\footnotetext{
${ }^{1}$ The standard periodization of Scheler's philosophical work is the following: early production (1899-1906); central or first phenomenological production (1908/1909-1922); last or second phenomenological production (1923-1928) [85, $108]$.

${ }^{2}$ The Munich circle was established around 1902. It was formed mainly by Lipp's ex-students, previously adherent to the Akademischer Verein für Psychologie founded by Lipps in 1895 [18]. Moving to Gottingen-where Husserl was first extraordinary professor, and then, from 1906, ordinary professor-, Lipp's exstudents such as Daubert, Conrad and Reinach founded the Gottingen circle. This circle included also few Husserl's students, e.g., Schapp and von Sybel, and became consolidated in 1907 with the establishment of the Göttingen philosophische Gesselschaft. Starting from the 1913 publication of the first book of Ideen zu einer reinen Phänomenologie und phänomenologischen Philosophie, most of Gottingen phenomenologists became critical with regard to Husserl's transcendental phenomenology, outlined for the first time in this work. As known,
}

Notwithstanding different theoretical solutions, proponents of this tradition share a view of phenomenology that goes against Husserl's constitutive approach to foundational issues, which had been developed in 1913 in connection to the new method of the phenomenological epoché [22]. Simplifying, the following two points are crucial in their proposals [23]:

1. Anti-psychologism. Early phenomenological realists look at Husserl's Prolegomena to Pure Logic, the first book of his groundbreaking Logical Investigations, as the work that definitively overcomes psychologism, the philosophical trend that reduces logical to psychological laws, objectual domains to psychical contents.

2. Object-orientated phenomenology. Following the spirit of the 1901 Logical Investigations' second book, phenomenological realists inquire the "essence" (Wesen), namely the synthetic a priori laws, either material or general-formal, thanks to the methods of the "reduction" of phenomenal data to their essential legality (eidetische Reduktion), and the "abstraction of the form" (Abstraktion) from the essence [24].

One of the main leading figures of the Munich and Gottingen circles was Max Scheler, who from 1911 regularly lectures in Gottingen-in coffee houses and private rooms, because he was suspended from teaching in Munich-focusing on a criticism towards Husserl's transcendental phenomenology.

Starting from a fragmentary suggestion detectable in Scheler's early phenomenological work, in what follows I will introduce a semiotic interpretation of intentionality based on a relational reading of formal ontology. This is articulated in three main steps: 1) the distinction between general (synthetic) and pure (analytic) objective forms or categories through two different notions of form, an abstractive and operational one; 2) the re-configuration of the analytic pure objectivity as a synthetic category; 3) a signdriven synthesis of the object, occurring within the ontological sphere of the signification processes (semeiosis), which are understood as meaning-making processes, and hence outside the epistemological sphere of the subjective self-consciousness. ${ }^{3}$ The proposed interpretation aims at

this project follows the development of the phenomenological reduction, that was at the beginning only the Cartesian way, namely the methodical suspension (epoché) or "bracketing" of the natural attitude of experience, either ordinary or scientific, in that thematically expressed in factual judgments concerning the there-being (dasein) of the object in the actual world [83]. The so-called Seefelder Blätter dating back to the summer of 1905 , offer the first evidence of Husserl's methodological quest [90].

${ }^{3}$ It is worth noticing that phenomenology or phaneroscopy is a fundamental field of research within C.S. Peirce's semiotic theory of categories. It aims at categorizing the predicative and relational features of the object regardless of their cognitive values. "Object" here is not a semiotic representation, namely the correlate of a sign or triadic relation, but a "phaneron", that is a presence or phenomenon manifesting itself in its nature. Peirce's phaneroscopy aims also at describing the relational categories through an algebraic-diagrammatic representation of them [75-78]. In what follows I will re-propose Peirce's categorial approach from the within of Schelerian phenomenology. It is important to be clear that I will not refer to Scheler's well-known discussion of Peirce's 
strengthening the traditional (inter) subjective approach of phenomenology to the categorial study with the "in the third person" objective approach distinctive of semiotics, sharing in principle with the former a common pre-logical and hence ante-predicative level of enquiry.

Mathematical Category Theory (CT) provides a rigorous framework in developing this unification step because it deals with relational structures (relational categories) underpinning the predicative ones. Following the direction suggested in previous studies [25-29], I will show that CT is that new mathematical theory which "may offer possibilities previously not available for a formalization of consciousness" [6]. However, in my proposal phenomenology is not stricto sensu naturalized because it preserves both the descriptive and transcendental perspective. The former will be re-formulated according to a "categorial refinement" of the semiotic phenomenology aiming at describing the formal features of phenomena through a mathematical representation of them. The latter will be developed in continuity with the so-called "Post Modern transcendental of language" [30-31] or, rather, of sign, which has been developed during the last years by authors like Deely, Maddalena, Harney, and Basti [32-34, 12, $13,4]$.

\subsection{Structure of the Paper}

The scheme of the paper is the following: in $\S 2$ I will outline Scheler's early account of formal ontology and the theory of "functionalization of the essential knowledge" (Funktionalizierung der Wesenserkenntnis) that provides a continuity between reality and consciousness through a dialectical genesis of the intentional structures. In $\S 3$ Scheler's proto-relational reading of the object's formal identity will be developed in a two-dimensional research program that involves also a semiotic study of the pure objectivity. This study will be carried out within the rigorous framework of CT, whose basic notions will be thus introduced. On this basis, I will start using CT to systematically investigate the idea of a phenomenological dialectics. Concluding, I will show how the theoretical task involved in the construction of a "broader conception of phenomenology" can be addressed from the perspective of the research program presented in $\S 3$.

\section{The Historical Background}

A consideration is crucial for the introduction of Scheler's early account of formal ontology: the understanding of the discipline developed by the Munich and Gottingen phenomenological realists. They distinguish between general formal ontologies interested in the synthetic objective categories of the real being organized into the highest

philosophical pragmatism, systematically treated in the 1926 essay Erkenntnis und Arbeit. The ratio is that after 1922 Scheler's notion of objective form or category is no longer the same as that defended in his early phenomenological production, which will be my reference [118]. material genera and a pure formal ontology that explores the "empty", analytic formal region of the logical being, i.e., the "objectivity in general" (Gegenständlichkeit überhaupt) [35]. Along this line, Scheler detects two different notions of form, an abstractive and operational one, corresponding to general and pure formal ontologies, respectively.

Starting from this introductory remark, in the next subsection I will present what I maintain to be the architectonic structure of Scheler's early formal ontology.

\subsection{The Architectonic Structure of Scheler's Early Formal Ontology}

Scheler's early formal ontology has a multi-level structure. It includes a theory of the objectual forms exhibited by historical-cultural worldviews (Weltanschauungen) ${ }^{4}$ and a theory of the objectual forms exhibited by metaphysical ontology (Lehre von den Seinsformen) conceived as an autonomous, self-constituting worldview [36]. Both the theories are developed in accordance with the method of eidetic reduction and the abstraction of the form. Accordingly, they are both directed to the study of the synthetic categories, the forms of real being organized into the highest material genera [37]. Schelerian formal ontology includes also a "pure theory of objectivity" (reine Gegenstandslehre) that investigates analytic categories, first of all the category of the "objectivity in general" [38, 37]. Thus, Scheler interprets formal ontology as a multilevel discipline involving a trivium of formal ontological subdisciplines with the corresponding classes of synthetic and analytic categories.

In this paper I will not expose the details of Scheler's formal ontological system, which have been already provided [39]. I will focus, instead, on Scheler's original proposal of a phenomenological dialectics and the connected fragmentary formulation of the pure objectivity as a synthetic category.

\subsection{The Theory of Functionalization of the Essential Knowledge}

The theory of functionalization of the essential knowledge was outlined for the first time in the posthumously edited essay Ordo Amoris of 1914-1916/1925 ${ }^{5}$, but it was systematically treated only in the 1921 work Probleme der

\footnotetext{
${ }^{4}$ Between 1908/1909 and 1922 Scheler's understands phenomenology as a transcendental cultural eidetic, i.e., a descriptive and at the same time critical theory that, in evidencing the essences and essential nexuses underlying historical and ethnical-social-cultural worldviews (Weltanschauungen), grounds them as situated systems of real ontology and knowledge [117]. The main sources of Scheler's early interpretation of the notion of "worldview" are W. Dilthey, H. Gomperz, and above all W. von Humboldt. Scheler opposes explicitly Husserl's criticism against Dilthey's account of the philosophy of worldviews, which was exposed in the 1911 paper Philosophie als strenge Wissenschaft [36]. Starting from the mid-Twenties, Scheler is mainly confronted with Max Weber and his school's interpretation of the notion [99].

${ }^{5}$ The first draft of the essay dates back to 1913-1914. In 1925 Scheler published a chapter with the title Phänomenologie und Erkenntnistheorie in the collection Schule der Philosophie edited by J. Feldmann. The draft and the published chapter are now available [43].
} 
Religion [40]. As anticipated, with this theory Scheler argues for a dialectical genesis of intentionality: his aim is to provide a suitable alternative to the Kantian-inspired transcendental programs, contrasting the logical identification of the object with an object-driven structuration of consciousness conceived as a situated system of spiritual functions that "increase" (wachsen) or "decrease" (nehmen ab) throughout different ages and ethnical-socialcultural groups [38]. Scheler proposal develops in a strict comparison with, among others, A. Comte, J. S. Mill, L. Lévy-Bruhl, and E. Durkheim's "positivistic" (positivistisch) and "specialized" (specializiert) sociology of knowledge, as well as with H. Spencer's neo-Darwinian evolutionism [41]. However, his point of reference is Hegel's objective dialectics. In contrast to the Hegelian idealistic interpretation, Scheler suggests the phenomenological notion of the essence as an intuitive self-given accessible via an essential insight (Wesensschau) [38]. His proposal extends also to a re-formulation of Hegel's objective dialectics wherein being, understood as a "subjective a priori" (subjektive Apriori), is derived from the essence, the objective a priori. Let me consider this crucial point more closely.

According to Scheler, functionalization (funktionalizierung) is a process that is dialectical in nature [38]. It combines in fact two movements, namely subjectivation and reobjectivation pertaining to a pre-self-given: the essence intended as an object of tradition (Tradiktion), and hence a pre-datum in the sphere of passivity based on historical sedimentations and ethnical-social-cultural perspectiveness. In particular, either the essential matter or form are functionalized: the former when it turns into the corresponding class of predication; the latter when it turns into the propositional form (subjectivation). In having true values, the propositional form allows the identification of the actual predication domain among the essence's possible bearers (reobjectivation). Functionalization can't be thus reduced to biological and/or psychological genesis.

To our purpose, two points are relevant in Scheler's suggestion: 1) re-objectification is based on what is called by the author "selection" (Selektion), i.e., relations of indication by sings [38]. Previously, it had been even contrasted with essential relations [42, 37]. However, in general, differently from Husserl's semiological view according to which "sign" is a conceptual object consisting in a signifier (the name of sign or the "sign-vehicle") and a signified (the referred meaning), ${ }^{6}$ Scheler doesn't reduce sign relations to conscious awareness. He focuses, instead, on semiotic triadic relations: the vehicular function of the sign generates the reference of a qualitative ground (first) to correlates (second) and an interpreting act or relation (third). Accordingly, in his opinion, selection provides a relational ontology, wherein the identification of the object belonging to the actual

\footnotetext{
${ }^{6}$ As recently demonstrated, Husserl's view on sign is strongly influenced by the semiology not only of his teacher Franz Brentano, but also of Leibniz through Trendelenburg's interpretation of his characteristica [81].
}

predication domain of the essence occurs locally via signification processes that "break" the transcendental unity of the essence. Scheler speaks of "existentially relative" (Daseinsrelativ) objects where the copula acts as a contextdependent medium between the propositional terms referring to an interpreting act or relation [36, 43]. 2) Against the Hegelian "power of the negative", Scheler stresses an ontological foundation of non-contradiction [41, 42]. Moreover, he develops a pluralistic theory of the dialectical negation that is, dually, an intuitionistic, and hence paracomplete, and paraconsistent negation [44]. ${ }^{7}$ Until 1922 this was maybe the most powerful alternative that Scheler had elaborated with regard to the Hegelian dialetheism according to which there can be "dialetheia", i.e., nondualism between truth values, and hence true contradictions.

In strict connection with the theory of functionalization of the essential knowledge Scheler elaborates an unconventional understanding of the pure objectivity as a synthetic category. This position, that assumes the author's general account of the relationship between philosophy and religion, ${ }^{8}$ focuses on the description of a dual homomorphism among the intentional and causal structure, consciousness and reality. Scheler utilizes the image of two languages, the "inner" language of consciousness which, with regard to the structure, mirrors the "outer" language of things (Sprache der Dinge selber), wherein reality itself, viz. things in their properties and relations, are experienced as the "field of expression" (Ausdrucksfeld) of the divine's creational power [38]. ${ }^{9}$ In this way, starting from his phenomenology of the sacred and religious experience, Scheler utilizes the sign triadic relation for drawing up a realistic foundation of pure objectivity. This is based on the dual correspondence between the logical and ontic structure. The latter consists of primary causal relations that are disclosed to the human mind by the sacred/religious experience of reality, wherein things give themselves as indexes (Fingerzeige) "pointing to" the Creator [38].

\footnotetext{
${ }^{7}$ See J.-Y. Béziau's contributions for the pluralistic theory of negation and the modal context of its interpretation $[119,120]$. Scheler seems to interpret in modal terms the duality between paracompleteness and paraconsistency within his pluralistic theory of dialectical negation [38]. He focuses particularly on the paraconsistent side, correctly conceptualizing it as "pseudo-difference" [38, 44].

${ }^{8}$ In the first part of Probleme der Religion Scheler systematically investigates the relationship between philosophy, especially metaphysics, and religion, arguing for a "conformity" (Konformität) between the two. The main thesis, which is proposed by the author again in the third part of the book, is that of the independence of religion from metaphysics, notably with regard to its foundation. On the other hand, once clarified in its more fundamental evidences, metaphysics discovers its dependence on religion autonomously. This concerns the knowledge of the personality of the world's primary cause. According to Scheler, the attribution of a creational power to the primary cause, making it of a personal nature, is not a matter of spontaneous knowledge but of both the absolute person's positive and natural self-revelation. On this basis, Scheler argues for the genetic primacy of the sacred/religious consciousness in comparison to the metaphysical one with regard to the experience of the essential and existential order of being.

${ }^{9}$ In this case the analogical nature of the sign reference is highlighted by the author $[38,95]$. To note that this is compatible with the phenomenological framework, in that Scheler is describing sacred/religious phenomena manifesting an originary consciousness about the so- and there-being of things.
} 
Summing up, Scheler was defending a realistic stance on pure objectivity, trying to represent it not as an analytic but as a synthetic category. To this aim, he follows a very original research path whereby the sign-driven account provided for the actual object in the context of the theory of functionalization of the essential knowledge is extended to pure ontology.

\section{A Categorial Framework for the Semiotic Phenomenology}

\subsection{Some Basic Notion of Category Theory}

In his contributions to the algebra of relatives and graph theory Charles S. Peirce gives a first rigorous account of the triadic relation underpinning the predicative nexus, and hence the formal identity of the object [45-48]. Beginning in 1940, Tarski and his students gradually rediscovered the main aspects of Peirce's relational systems as regards mathematical objects, developing the contemporary research area of abstract algebra that is called relation algebra [49]. Tarski and Givant first demonstrated that to faithfully express Peano arithmetic, and almost all axiomatic set theories, an axiomatic version of a triadic relation algebra is sufficient [50]. It is precisely this result in relation algebra that is one of the main motivations for developing $\mathrm{CT}$ in contemporary mathematics.

However, in its early development period from the publication of the 1942 and 1945 Eilenberg and Mac Lane's pivotal papers until Grothendieck and Kan's contributions respectively to algebraic topology and homotopy theory in the late '50s, CT was interpreted in the spirit of Klein's Erlangen Programm [51]. Starting from the '60s, Freyd and Lawvere's work clarifies progressively the theoretical difference between Klein's notion of structural invariance and the categorial notion of functoriality, that interests a given coherency in the transformation of a structure [52]. Lawvere also shows how categories can be utilize for the study of formal logic and the foundations of mathematics. In the main time Lambek starts applying categorial methods to proof theory. On this basis, most of today's category theorists look at CT as a unification theory expressing a universal mathematical language that allows them to interpret highly structured mathematical notions, such as cohomotopy, cohomology, and coalgebra, which are crucial for contemporary theoretical sciences, especially theoretical physics and theoretical computer science [53]. Furthermore, CT seems to provide contemporary mathematicians with a higher level of generalization then ordinary Set Theory (ST), giving them the possibility to formalize also "object-free categories", and hence "category-free categories", namely categories without categories in the predicative sense [5456]. ${ }^{10}$ Reference [57] provides an overview of the current

\footnotetext{
${ }^{10}$ The idea is to "show that it is perfectly possible to get rid of the identity of objects by definition [...] This can be achieved by defining category exclusively in terms of morphisms and identity morphisms (objectless, or object free,
}

debate on identity criteria and foundations as to CT.

Simplifying, it is possible to say that the fundamental notion of CT is that of arrow or morphism: objects corresponding in $\mathrm{CT}$ to identity morphisms, i.e., reflexive morphisms whose domain and codomain coincide, so that they do not constitute a primitive of the theory. Actually, CT's primitive notions are such:

Morphism or arrow, namely the orientated relation that generalizes logical and mathematical notions such as predicate, function, and operator; domain-codomain, that is the map that assigns to the relation a direction from a source (domain) to a target (codomain), making it a morphism or arrow; morphisms composition, i.e., two or more morphisms are arranged in a sequence to form a new morphism.

Thus, category theorists do not look at relations as tuples of objects. CT is in fact a general theory of structure based on the notions of morphism, domain-codomain map, and morphisms composition. This offers a more general definition of structure than what is provided by ST which refers to elements and sets. In fact, as has been anticipated, within CT an object or set $X$ is defined through the identity morphism $i d_{X}: X \rightarrow X$ satisfying the law of unity. Namely, for two object $X, Y, i d_{X} \circ f=f=f \circ i d_{Y}$, where $<\circ>$ stands for composition. The set theoretic notion of function is generalized in the categorial notion of morphism, e.g. the injective function becomes an injective homomorphism called monomorphism [58]. The set theoretic operation of functions composition $g \circ f: X \rightarrow Z$ for functions $f: X \rightarrow Y$ and $g: Y \rightarrow Z$ is generalized in the operation of morphisms composition, that satisfies associativity. Namely, for $f, g, h, h \circ(g \circ f)=(h \circ g) \circ f$.

So, broadly speaking, CT's categories are not predicative but relational and hence semiotic categories: a relational category is any collection of morphisms, compositions of morphisms and objects, i.e., identity morphisms, that preserves the structure up to isomorphism (uniqueness condition).$^{11}$ Being more precise, a category $\mathrm{C}$ consists of a collection $\mathrm{Ob}(\mathrm{C})$ of objects $A, B, C, \ldots$; collection $\operatorname{Mor}(\mathrm{C})$ of morphisms; maps dom, cod: $\operatorname{Mor}(\mathrm{C}) \rightarrow O b$ (C). A morphism with domain $A$ e codomain $B$ is written $f: A \rightarrow B$. For each pair $A, B$ there exists a collection of homomorphisms;

Composition maps $c_{(A, B, C)}: \mathrm{C}_{(A, B)} \times \mathrm{C}_{(B, C)} \rightarrow \mathrm{C}_{(A, C)}$ for triples $A, B, C . c_{(A, B, C)}(f, g)$ is written $g \circ f$ and respects associativity;

Identity morphisms $i d_{A}: A \rightarrow A$ (sometimes written $1_{A}$ ) for each $A$ that belongs to $O b$ (C), i.e., $A \in O b(\mathrm{C})$ respecting unity [58].

There exist different criteria for classifying categories. The

category) and, analogously, by defining category theory entirely in terms of functors and identity functors (categoryless, or category free, category theory)" [56, p. 447].

${ }^{11}$ A morphism $f: X \rightarrow Y$ is an isomorphism, $X \cong Y$, if there is an arrow $g: Y \rightarrow X$ such that $f \circ g=i d_{Y}$ and $g \circ f=i d_{X}$. 
most known are the concrete/abstract criterion and the small/large criterion. A category $\mathrm{C}$ is concrete if $\mathrm{Ob}(\mathrm{C})$ is a set or a structured set, otherwise $\mathrm{C}$ is abstract. $\mathrm{C}$ is small if $O b(\mathrm{C})$ and $\operatorname{Mor}(\mathrm{C})$ are sets or structured sets; otherwise $\mathrm{C}$ is large. Concrete categories are e.g. Set (sets and functions), Pos (partially ordered sets and monotonic functions), Top (topological spaces and continuous functions), Bool (Boolean algebras and homomorphisms between Boolean algebras). Rel (sets and relations) is a well-known example of an abstract category. Grp (groups and homomorphisms between groups) is small, whereas Set is large.

Again, simplifying, the basic idea underlying CT is to capture identities of structures, technically homomorphisms between theories, that are not detectable through the predicative analysis (unification goal) [59]. "Functor" is the operation mapping objects and arrows of a category into another category. In other terms, it is a morphism between categories that preserve compositions and identities, so that between the two categories there exists a homomorphism up to isomorphism. Generally, a functor is covariant, that is, it preserves arrows directions and composition orders. Even if a functor connecting two categories is contravariant, i.e., reverses all the arrows directions, and all the composition orders, the categories are homomorphic up to isomorphism. For two categories C, D, a covariant functor F : C $\rightarrow$ D consists of

a map that for all $A \in O b(\mathrm{C})$ assigns $F A$ to $O b(\mathrm{D})$

a map that for all $f: A \rightarrow B \in \operatorname{Mor}(\mathrm{C})$ assigns $F f: F A \rightarrow F B$ to $M o r(D)$ in a way that $F(g \circ f)=F g \circ F f$ and Fid $_{A}=i d_{F A}$.

A contravariant functor $f: C \rightarrow D$ is a covariant functor from the opposite category $f: C^{O P} \rightarrow D$ or to the opposite category $f: C \rightarrow D^{O P}$, which reverses all the arrows directions, and all the composition orders of the corresponding category.

Concluding, it is important to recall the role played by diagrams in CT. A diagram is the analogue of an indexed family in ST, i.e., a function together with its domain and image. In a category $\mathrm{C}$ a diagram $D$ is a functor $D: \mathrm{J} \rightarrow \mathrm{C}$ from a fixed index category to $C$. $J$ is usually called the scheme of $D$. If $\mathrm{J}$ is a category of finite partially ordered sets (posets), $D$ can be visualized by a directed graph whose nodes are objects of $\mathbf{J}$ and whose arcs are morphisms of $\mathbf{J}$ Morphisms and identity morphisms are expressed as compositions. Commutative diagrams express the uniqueness of morphisms and usually are "pasted together" to compose complex diagrams (Figure 1).

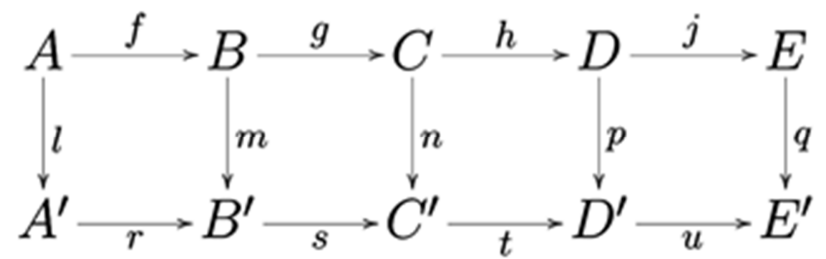

Figure 1. Complex diagram with many objects and morphisms. Source: https://en.wikipedia.org/wiki/Commutative_diagram.

With this background of CT in mind I can start justifying the use of a triadic relational semantics, in the categorial sense, for interpreting phenomenological pure objectivity. As I will explain in the final section of the paper, this is a first but crucial step towards a theoretical unification of transcendental and naturalized phenomenology.

\subsection{Framing Synthetic Objectivity}

The first thing to notice is that object-free categories are not useful in our case. In fact, phenomenological ontology necessarily considers object as a fundamental notion even when, after following Scheler, is the triadic relation of the sign that underlies the formation of the intentionality's object pole. The application concerns therefore the category of elementary topoi, that generalizes the category of topoi and geometric morphisms adding to the not object-free category Set of sets and functions a notion of localization [60]. This notion, that provides a direct connection between geometry, ontology, and logic (see below), is crucial in order to systematically grasp the selective machinery of sign, as we are going to show in this paragraph.

Elementary topoi are cartesian closed categories, namely categories having the terminal object, binary products, and exponential objects, with pullbacks and a subobject classifier, that is an object (identity morphism) representing the categorial abstraction of the subset of a set and of its characteristic function. We need to be aware of the universal nature of the following definitions wherein morphisms are universal, i.e., unique up to (unique) isomorphism. ${ }^{12}$

Let $\mathrm{C}$ be a category, an object $F$ is final (written 1 ) in $\mathrm{C}$ if for all $A \in O b(\mathrm{C})$ there is a morphism $f_{A}: A \rightarrow 1$ that satisfies unity up to isomorphism. For two objects $\mathrm{A}$ and $\mathrm{B}$ in $\mathrm{C}$, a pairing $\mathrm{A}, \mathrm{B}$ is a triple $\left(P, \pi_{1}, \pi_{2}\right)$ with projection morphisms $\pi_{1}: P \rightarrow A, \pi_{2}: P \rightarrow B$. The pairing $\mathrm{A}, \mathrm{B}$ form a binary product if the following universal condition is satisfied: for every object $\mathrm{X}$ and pair of morphisms $f_{1}: X \rightarrow A, f_{2} ? X \rightarrow B$, there exists a unique morphism $g: X \rightarrow P$ such that the following diagram commutes.

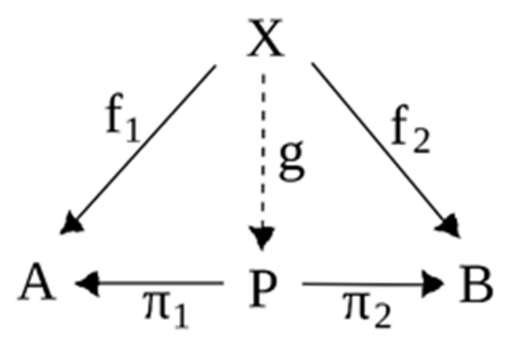

Figure 2. Commutative diagram for the binary product $\left(P, \pi_{1}, \pi_{2}\right)$. Source: https://en.wikipedia.org/wiki/Product_(category_theory).

Again, for two objects $\mathrm{A}$ and $\mathrm{B}$ in $\mathrm{C}$, an exponential object $A^{B}$ is an object in $\mathrm{C}$ with an evaluation map

\footnotetext{
${ }^{12}$ Universal definitions and constructions are ubiquitous in CT. Within the framework of CT, universality means canonicity in the "solutions to problems of construction" (Abramsky et al., 2011, p. 42). In other terms, the existing solutions are unique up to (unique) isomorphism.
} 
$\varepsilon_{(A, B)}: A^{B} \times B \rightarrow A$ such that the following universal condition is satisfied: for all $f: C \times B \rightarrow A$, there exists a unique morphism $f^{\prime}: C \rightarrow A^{B}$, the so-called transpose of $f$, such that the following diagram commutes.

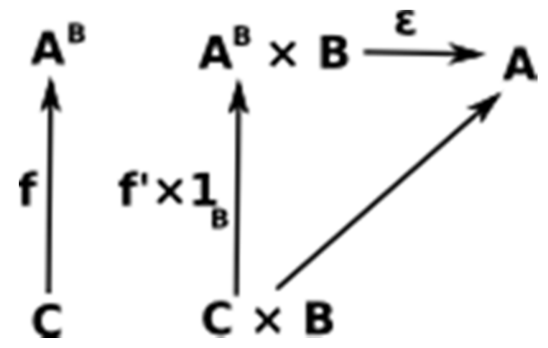

Figure 3. Commutative diagram for the exponential object $A^{B}$. Source: www.euclideanspace.com/maths/discrete/category/compound/exponent/inde x.htm.

Topoi (topoi and geometric morphisms) is a category that is much like Set (sets and functions), but it has also a notion of localization. A topos is a sheaf ${ }^{13}$ on a small category ("site") equipped with its Grothendieck topology. ${ }^{14}$ Let $X, Y$ be two topological spaces. A continuous function induces a direct image functor $f_{*}: \mathrm{Sh}(X) \rightarrow \mathrm{Sh}(Y)$ and an inverse image functor $f^{*}: \operatorname{Sh}(Y) \rightarrow \operatorname{Sh}(X)$ between topoi of the sheaves $\operatorname{Sh}(X)$ and $\operatorname{Sh}(X)$ over $X, Y$. A geometric morphism between arbitrary topoi generalizes this situation. For the general theory of geometric morphisms, each topos is a site within the category of presheaves represented as a contravariant functor from an arbitrary category $\mathrm{C}$ to Set. Namely, F : $C^{O P} \rightarrow$ Set. Elementary topoi generalize this situation referring to categories other than Set.

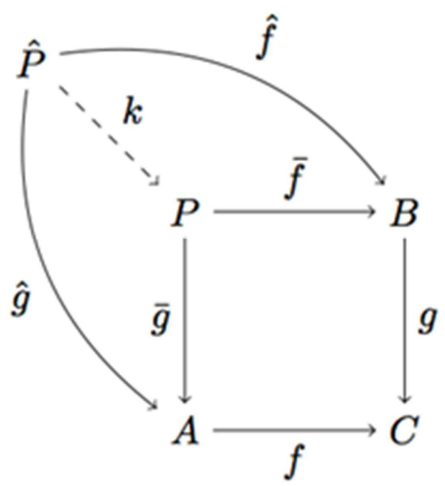

Figure 4. Commutative square for the pullback $(P, \bar{f}, \bar{g})$ and the universal condition. Source: https://pdp7.org/blog/2011/02/how-to-drawcommutative-diagrams-in-latex-with-tikz/.

Given the morphisms $f: A \rightarrow C, g: B \rightarrow C$ of a category $\mathrm{C}$, their pullback is an object $P \in \mathrm{C}$ with morphisms $\bar{f}$ :

\footnotetext{
${ }^{13}$ Roughly speaking, a sheaf is a mathematical tool that allows us to define things locally, attaching them to the open sets of a topological space.

${ }^{14} \mathrm{~A}$ Grothendieck topology is usually defined on an arbitrary category through the identification of the set of morphisms that behave like covering sieves for the category's objects thought as spaces.
}

$D \rightarrow A, \bar{g}: D \rightarrow B$ such that the square diagram in Figure 4 commutes. In order to be universal the pullback $(\mathrm{P}, \bar{f}, \bar{g})$ has to satisfy the following condition: if $\hat{P}$ is another object with morphisms $\hat{f}: \hat{P} \rightarrow A, \hat{g}: \hat{P} \rightarrow B$ such that $f^{\circ} \hat{f}=g^{\circ} \hat{g}$, then there a unique morphism k: $\hat{P} \rightarrow P$ such that $\bar{f} \circ k=\hat{f}$ and $\bar{g} \circ k=\hat{g}$.

A subobject classifier (Figure 5) is a monomorphism true $: 1 \rightarrow \Omega$ from the terminal object 1 to $\Omega$, the so-called truth object of $C$, such that all pullbacks of true exist in the category and, for any monomorphism $f: A \rightarrow B$, there is a unique morphism $\mathcal{X}_{f}: D \rightarrow \Omega$ called the classifying map of $f$.

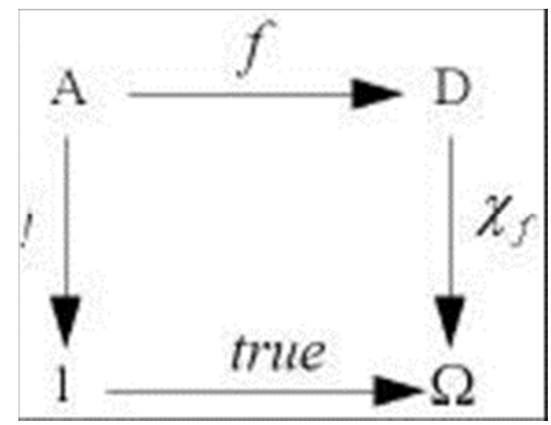

Figure 5. Subobject classifier pullback square. Source: https://www.researchgate.net/figure/Category-subobject-classifier-pullbacksquare_fig15_257644873.

The category $\mathrm{E}$ of elementary topoi is a cartesian closed category with pullbacks and a subobject classifier.

For our aims the relevant aspect is that in an arbitrary elementary topos subobjects form an equivalence class of monomorphisms, $\operatorname{Sub}_{\mathbf{E}}(A)$, over an object $A$ of the category trough the pullbacks' isomorphism. This makes clear the local detection of the qualitative ground and correlates that distinguishes semiotic ontologies, whose significance for logic, more precisely for semantics, will appear in the next section. Technically, even if Set (sets and functions) can be seen as an elementary topos where $\Omega=\{0,1\}$ and true $: 1 \rightarrow\{0,1\}$, and where, because the monomorphism is an inclusion morphism, there is the canonicity of pullbacks, this situation is not generalizable for any arbitrary elementary topos. In fact, in arbitrary elementary topoi morphisms are not functions necessarily. Accordingly, there is no universal notion of equivalence applicable to all subobjects, that are considered as an equivalence class of monomorphisms over $A \in O b(\mathrm{E})$ [61]. This first result can be developed through an application of the formal duality principle, following Scheler's idea of the dual homomorphism underlying the category of pure objectivity which has been focused on in the previous paragraph.

According to its categorial systematization, the formal duality principle states that, given a category and an endofunctor on a category onto itself, the contravariant application of the functor links a category to its opposite [51]. The contravariant application of the endofunctor applies also to the so-called functor categories, composed by 
functors as objects and morphisms between functors ("natural transformations") as morphisms [58]. With the dual functorial categories of slice and coslice, respectively over and under an arbitrary object of E, we can represent the dual correspondence between the structures of converse membership and membership. Let me look more at this point, recalling that in the category Set membership is a function, $f: 1 \rightarrow A$, that determines an element $\mathrm{x}$ of a set $A$, $x \in A$, as the f-image of the only member of the singleton subset $\{\mathrm{x}\}$ of $A$ [60]. In the category $\mathrm{E}$ of elementary topoi $f: 1 \rightarrow A$ is a morphism from the final object to an arbitrary object $A$. This morphism is an object in the coslice category under $A$ which generalizes $1 \downarrow$ Set, where 1 is the singleton, providing a universal definition (unique up to unique isomorphism) of the category of pointed sets, namely sets with a base point, i.e., a chosen element, and pointed maps. As a category, a pointed $\operatorname{set}\left(X, x_{0}\right)$, where $x_{0} \in X$, is an upto-isomorphism-preserved structure with a single operation ( 0 -ary operation) that selects the base point. Pointed maps are homomorphisms of such algebras.

Slice and coslice categories are special cases of a functorial category called comma category whose general form is the following: if $\mathrm{S}: \mathrm{A} \rightarrow \mathrm{C}$ and $\mathrm{T}: \mathrm{B} \rightarrow \mathrm{C}$ are functors, the comma category $S \downarrow T$ consists of objects $(A, B, h)$, where $A \in O b(\mathrm{~A}), B \in O b(\mathrm{~B})$ and $\mathrm{h}$ is a morphism in $\mathrm{C}, h: \mathrm{S}(\mathrm{A}) \rightarrow \mathrm{T}(\mathrm{B})$ and morphisms that are all pairs $(f, g)$, where $f: A \rightarrow A^{\prime}$ and $g: B \rightarrow B^{\prime}$, such that the following diagram commutes.

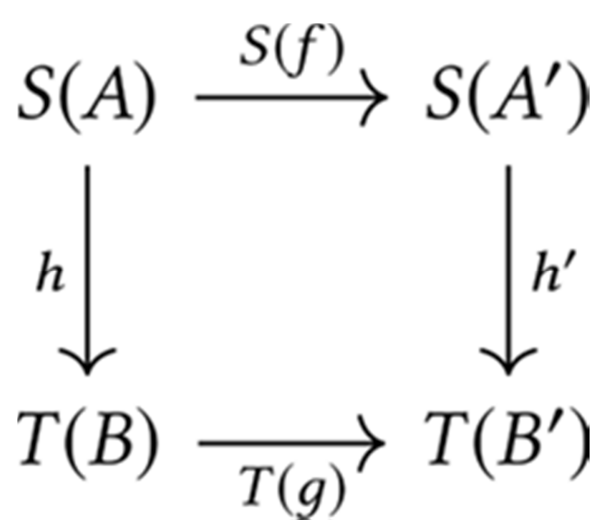

Figure 6. Commutative diagram for the comma category. Source: https://en.wikipedia.org/wiki/Comma_category\#Coslice_category.

Compositions are $\left(f^{\prime}, g^{\prime}\right) \circ(f, g)=\left(f^{\prime} \circ f, g^{\prime} \circ g\right)$, and for an object $(A, B, h)$ an identity morphisms is the couple $\left(i d_{A}, i d_{B}\right)$.

The special case of slice category $\mathrm{A} \downarrow A^{*}$ assumes that $\mathrm{A}=\mathrm{C}$ then $F$ is an identity functor, and $\mathrm{B}=1$ i.e., a category with one-object $*$ and one-morphism, then $T\left({ }^{*}\right)=A^{*}$ for some object $A$ in A. The slice category over $A^{*}$ consists of objects $\left(A,{ }^{*}, \pi_{A}\right)$, where $\pi_{A}: A \rightarrow A^{*}$, and morphisms $\left(f, i d^{*}\right)$ from $\left(A,{ }^{*}, \pi_{A}\right)$ to $\left(A^{\prime},{ }^{*}, \pi_{A^{\prime}}\right)$ such that the following diagram commutes.

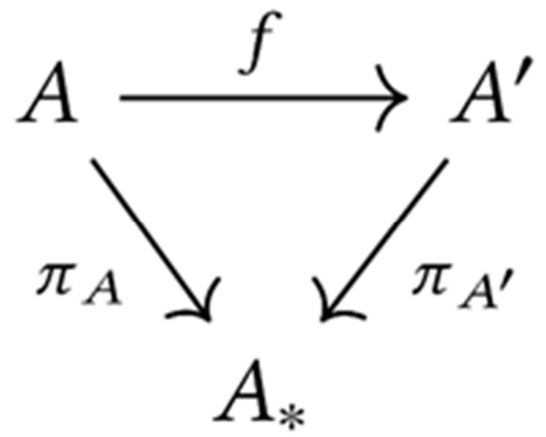

Figure 7. Commutative diagram for the slice category. Source: https://en.wikipedia.org/wiki/Comma_category\#Coslice_category.

The dual notion is that of coslice category $\mathrm{B}^{*} \downarrow \mathrm{B}$ under $B^{*}$, where $F$ has domain 1 and $G$ is an identity functor. This category consists of objects $\left(B,{ }^{*}, l_{B}\right)$, where $l_{B}: B^{*} \rightarrow B$, and morphisms $\left(i d^{*}, g\right)$ from $\left(B,{ }^{*}, l_{B}\right)$ to $\left(B^{\prime},{ }^{*}, l_{B^{\prime}}\right)$ such that the following diagram commutes.

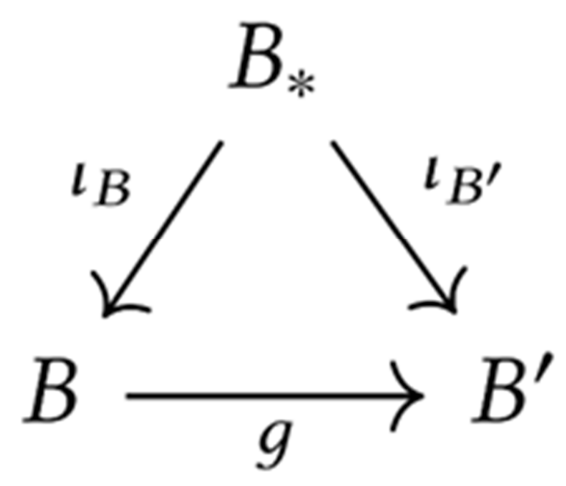

Figure 8. Commutative diagram for the coslice category. Source: https://en.wikipedia.org/wiki/Comma_category\#Coslice_category.

Assuming $\mathrm{E}$ as the codomain category, the representation of the comembership/membership dual correspondence is made effective by the duality between the slice and coslice category respectively over and under the object of an elementary topos.

\subsection{A Sketch of Internal Reasoning}

The so-called topos logic is the best-known example of the new categorial framework for representing classical as well as non-classical logics, the so-called internal reasoning, characterized by an "internalization" of logic in its own relational category $[61,52]$. Detecting a universe of discourse which is local, in that restricted to subobjects, internal reasoning is essentially aimed at overcoming the incompleteness limit of the classical formal semantics, formulated within the framework of ST. As known, this limit is due to the necessary recourse to an intrinsically incomplete higher-order predicative calculus, because of Tarski and Gödel's theorems on truth-function for proving truth in classical formal semantics.

One of the first philosophical application of the internal 
reasoning is Lawvere's study of the Hegelian dialectical notions of unity-and-identity-of-opposites and Aufhebung, which is based on the following three technical tools: adjoint functors, adjoint modalities and levels [62-65].

Let $\mathrm{F}: \mathrm{C} \rightarrow \mathrm{D}, \mathrm{G}: \mathrm{D} \rightarrow \mathrm{C}$ be two functors, a natural transformation $\theta: F \rightarrow G$ is a morphism between functors that respects naturality, i.e., is a family of morphisms $\left\{\theta_{A}: F A \rightarrow G A\right\}_{(A \in O b(\mathbf{C}))}$ of $\mathrm{D}$ such that for all $f: A \rightarrow B$. $G f \circ \theta_{A}=\theta_{B} \circ F f$ (Abramsky and Tzevelekos 2011, p. 35). $\mathrm{F}$ and $\mathrm{G}$ are adjoint functors if there is a natural transformation $\theta_{A, B}: C(A, G(B)) \rightarrow D(F(A), B)$ for $A \in$ $O b(\mathrm{C})$ and $B \in O b(\mathrm{D}) .{ }^{15} F$ is the left adjoint to $G$ and $G$ is the right adjoint to $F$, written $F \dashv G$. An adjoint modality is an adjoint triple $(\mathrm{F} \dashv \mathrm{G} \dashv \mathrm{H}): \mathrm{C} \rightarrow \mathrm{D}$, i.e., a triple of functors $F: \mathrm{C} \rightarrow \mathrm{D}, G: \mathrm{D} \rightarrow \mathrm{C}, H: \mathrm{C} \rightarrow \mathrm{D}$ with adjoint functors $\mathrm{F} \dashv \mathrm{G}$ and $\mathrm{G} \dashv \mathrm{H}$, with $\mathrm{F}$ and $\mathrm{H}$ inducing maps that are both injective and surjective functions. Such a pair of categories and triple of functors is a unity-and-identity-of-opposites [62]. Let $\mathcal{T}$ be a topos. A level in $\mathcal{T}$ is the right adjoint's inclusion of an adjoint modality. There is an Aufhebung of the unity-and-identity-of-opposites when, given two levels $l_{1}$ and $l_{2}, l_{2}$ includes $l_{1}$, and this inclusion is minimal.

As seen, in criticizing Hegel, Scheler suggests an ontological foundation of non-contradiction and a phenomenological approach to the objective dialectics that is based on a pluralistic theory of the dialectical negation (duality between paracompleteness and paraconsistency). Starting from Lawvere's work, I will now introduce a sketch of internal reasoning in order to systematically grasp Scheler's ideas. Firstly, in this direction, I have to clarify the internalization procedure in so far as it concerns the category E of elementary topoi.

The internal logic of an arbitrary elementary topos is an intuitionistic higher order logic. Putting it in a very simple way, this can be proved by performing two steps: 1) the demonstration that $\operatorname{Sub}_{\mathbf{E}}(A)$ is a Heyting algebra, ${ }^{16}$ making topos logic intuitionistic; 2) the induction on $\operatorname{Sub}_{\mathbf{E}}(A)$ of the universal quantifier, making intuitionistic topos logic a higher order logic. Reference [61] develops exstensively steps 1) and 2). The most common language of topos logic is the so-called Mitchell-Bénabou language, that is an extension of the lambda calculus simply typed. ${ }^{17}$

Starting from Mortensen's contribution, category theorists have been proposing an inconsistency-tolerant or paraconsistent approach to topos logic resulting in the socalled complement-topos theory, where logical connectives are characterized dually with respect to standard topoi [6668]. Complement-topos theory is based on the observation that Brouwerian algebra, namely the dual Heyting algebra,

\footnotetext{
${ }^{15}$ An adjunction from $\mathrm{C}$ to $\mathrm{D}$ is therefore a triple $(F, G, \theta)$.

${ }^{16}$ Accordingly, there exist also Boolean topoi. In fact, every Boolean algebra is a special case of a Heyting algebra where, because of bivalency, implication is classically defined as $\neg a \vee b$.

${ }^{17}$ For the sake of completeness, I recall that model theory also has been reformulated within the framework of the internal reasoning. See [102] for the different approaches to the topic.
}

generates a logic whose duality with respect to intuitionistic logic is "as deep as topological" [69]. For it is sometimes called closed set logic [66]. For our purposes, the relevant point is that complement-topos theory makes clear the nature of the duality between intuitionistic and paraconsistent negation unifying algebraic and topological aspects. Moreover, on this basis, it is possible to clarify Scheler's ontological foundation of on non-contradiction.

Let $A \in O b(\mathrm{E})$ the negation object in $\mathrm{E}$ is defined by exponential and initial objects, namely $0^{A}$. According to the general condition of identity, the exponential object is an identity morphism $i d_{0^{A}}: 0^{A} \rightarrow 0^{A}$, whose evaluation map $0^{A} \times A \rightarrow 0$ grasps the trivialization of an inconsistent formula which is distinctive of the intuitionistic negation $\neg a=(a \rightarrow 0)$. Since $A \vee \neg A=A \prod 0^{A}$ it is not possible that $1 \rightarrow A \prod 0^{A}$ and hence $\perp: A \vee \neg A$. I.e.: the excluded middle does not hold. In complement-topos theory the negation object is defined by the coexponential and final objects, namely $1_{A}$. The identity of the coexponential object is $i d_{1_{A}}: 1_{A} \rightarrow 1_{A}$, whose evaluation map $1 \rightarrow A \times 1_{A}$ grasps the notion of pseudo-difference usually associated to the paraconsistent negation $\neg a=(1 \leftarrow a)$. Since $A \wedge \neg A=A \times 1_{A}$, it is not possible that $A \times 1_{A} \rightarrow 0$, and hence $\perp: \neg A \wedge A \rightarrow 0$. I.e.: the principle of Pseudo-Scotus does not hold. As emphasized by Angot-Pellissier, in this context non-contradiction is the morphisms adjoint to the identity morphism of the negation object, namely $0^{A} \times A \rightarrow 0$ [67]. ${ }^{18}$

However, to start systematically understanding Scheler's dialectical doubling another passage is crucial: the representation of the continuous aspect through the addition of internal algebraic topologies to both the truth structures defined on $\operatorname{Sub}_{\mathbf{E}}(A)$. Reference [70] shows how to internalize in the category $\mathrm{E}$ a Grothendieck topology. The so-called Lawvere-Tierney topology, ${ }^{19}$ structuring the theory of levels and hence making possible Lawvere's representation of the Hegelian Aufhebung, is a morphism $j: \Omega \rightarrow \Omega$ that satisfies the following axioms.

Preservation of truth: $j \circ$ true $=$ true;

Preservation of intersections: $j \circ \wedge=\wedge(j \times j)$;

Idempotence: $j \circ j=j$.

Estrada-Gonzáles (2015) recently emphasize the existence of a dual Lawvere-Tierney topology, which is a morphism $\vartheta: \Omega \rightarrow \Omega$ in $\mathrm{E}$ preserving falsity ( $\vartheta \circ$ false $=$ false), commuting with unions $(\vartheta \circ \vee=\vee \circ(\vartheta+\vartheta)$ ), and being idempotent $(\vartheta \circ \vartheta=\vartheta$ ). With both the Lawvere-Tierney and dual Lawvere-Tierney topology a "categorial refinement" of

\footnotetext{
${ }^{18}$ Thus, excluded middle is the morphism $1 \rightarrow A \prod 1_{A}$ adjoint to $i d_{1_{A}}: 1_{A} \rightarrow 1_{A}$.

${ }^{19}$ Category theorists speak also of "local operator" in that a Lawvere-Tierney topology is a closure operator on the subobject classifier or, equivalently, a monad over a poset. Because idempotence is a theorem related to the topology's closure and, according to the so-called modal type theory, modal operators are idempotent monads, a Lawvere-Tierney topology is also called a geometric modality.
} 
the phenomenological dialectics seems to be possible.
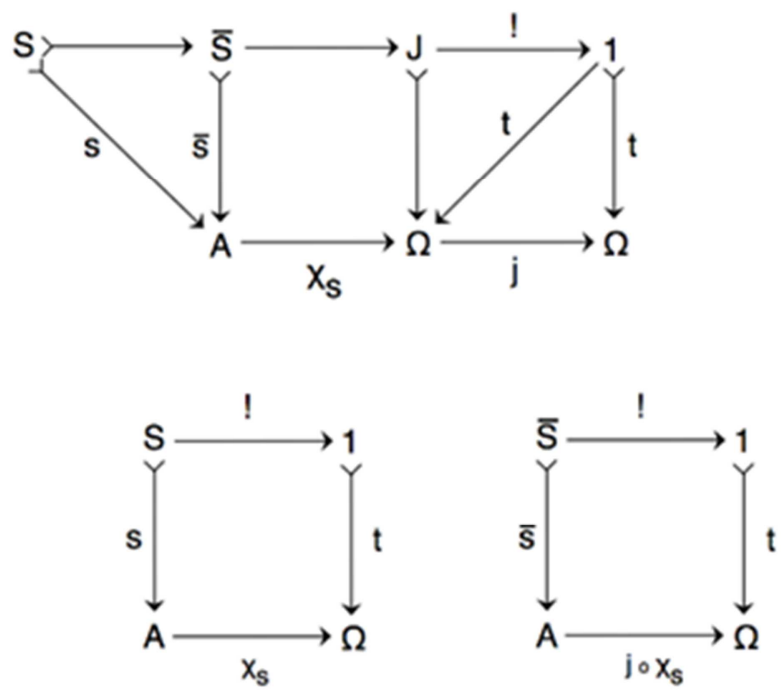

Figure 9. Commutative diagrams for the Lawvere-Tierney topology $j$. The bottom two pullback squares are contained in the top diagram, showing how j operates. Source: https://en.wikipedia.org/wiki/Lawvere-Tierney_topology.

\section{Conclusion}

In this paper I introduced the basics of a new categorial root to the so-called semiotic phenomenology, understood as a contemporary approach to the discipline which is able to settle the phenomenological dispute between the transcendental and naturalistic stance. Concluding, I intend to stress this point using as a reference Gallagher's emphasis on the question of a renewal of the phenomenological transcendental.

According to my proposal, that follows a fragmentary suggestion detectable in Scheler's early phenomenological work, intentionality can be reformulated as a triadic relation. The substitution of the adicity makes intentionality a "relatively degenerate" case of the sign relation ${ }^{20}$, thus justifying the shift towards a semiotic account of the phenomenological mind $[71,72]$. One has to be clear on the point that, in the light of this interpretation, the phenomenological mind specifies the universal third, i.e., the third term in semeiosis. Following this approach, namely in the direction of combining phenomenology and semiotics within a two-dimensional research program (semiotic phenomenology) that integrates the first- and third-person perspective, I have developed some Schelerian suggestions within the rigorous framework of $\mathrm{CT}$, wherein the categories are of a relational and hence semiotic type.

Based on this analysis, I claim that the so-called

\footnotetext{
20 "In the case of degenerate Secondness and Thirdness, Secondness and Thirdness are denominated extrinsically of the relationship involved. Degenerate Secondness and Thirdness are reducible to genuine Firstness and Secondness, which is what they are in themselves. They can be looked at as Secondness and Thirdness only by means of mental constructs. For example, the relation whereby I set down a coffee cup and you pick it up exemplifies Thirdness only in so fa as the mind connects two relationships $[\ldots]$ that are otherwise independent of one another" [71, p. 286]
}

"phenomenological data" can be "made continuous with the properties admitted by natural sciences", however without questioning their irreducibility to scientific data. The unification strategy that I propose focuses on a triadic relational semantics, in the categorial sense. As demonstrated, in fact, this can be established at the basis not only of the formalized languages of contemporary natural sciences, but also the "inner" language of consciousness, utilizing the Schelerian image revealing the universal third in the phenomenological mind.

\section{References}

[1] A. Ales Bello, Introduzione alla fenomenologia, Roma: Aracne, 2009.

[2] S. Gallagher, Phenomenology, Basingstoke: Palgrave Macmillan, 2012.

[3] J. Jansen, "Taking a Transcendental Stance: AntiRepresentationalism and Direct Realism in Kant and Husserl," in Husserl und die klassische deutsche Philosophie, F. Fabbianelli and S. Luft, Eds., Cham, Springer, 2014, pp. 79-92.

[4] G. Basti, "The Post - Modern Transcendental of Language in Science and Philosophy," in Epistemology and Transformation of Knowledge in Global Age, D. Zlatan, A cura di, London, IntechOpen, 2017, pp. 35-61.

[5] J.-M. Roy, J. Petitot, B. Pachoud and F. J. Varela, "Beyond the Gap: An Introduction to Naturalizing Phenomenology," in Naturalizing Phenomenology: Issues in Contemporary Phenomenology and Cognitive Science, J. Petitot, F. J. Varela, B. Pachoud and J. Roy, Eds., Stanford CA, Stanford University Press, 1999, pp. 1-80.

[6] L. Albertazzi, "Naturalizing Phenomenology: A Must Have?," Frontiers in Psychology, vol. 9, pp. 1-11, 2018.

[7] M. Aragona, "Phenomenology, Naturalism, and the Neurosciences," in The Oxford Handbook of Phenomenological Psychopathology, M. G. Giovanni Stanghellini, M. Broome, A. Raballo, A. V. Fernandez, P. Fusar-Poli and R. Rosfort, Eds., Oxford, Oxford University Press, 2018.

[8] S. Gallagher, "On the Possibility of Naturalizing Phenomenology," in Oxford Handbook of Contemporary Phenomenology, D. Zahavi, Ed., Oxford, Oxford Universitary Press, 2012.

[9] D. Zahavi, "Naturalized Phenomenology," in Handbook of Phenomenology and Cognitive Science, S. Gallagher and D. Schmicking, Eds., Dordrecht, Springer, 2010, pp. 2-19.

[10] D. Zahavi, "Naturalized Phenomenology: A Desideratum or a Category Mistake," Royal Institute of Philosophy Supplement, vol. 72, pp. 23-42, 2013.

[11] A. Bondi and F. La Mantia, Eds., "Phenomenology and Semiotics. Crossing Perspectives," Metodo. International Studies in Phenomenology and Philosophy, vol. 3, no. 1, 2015.

[12] M. Harney, "Naturalizing Phenomenology - A Philosophical Imperative," Progress in Biophysics and Molecular Biology, vol. 119, no. 3, pp. 661-669, 2015. 
[13] M. Harney, "Peirce and Phenomenological Naturalism," in For a New Naturalism, A. Gare and W. Hudson, Eds., Candor, NY, Telos Press, 2017, pp. 124-143.

[14] F. J. Varela, "Neurophenomenology: A Methodological Remedy to the Hard Problem," Journal of Consciousness Studies, vol. 3, no. 4, pp. 330-349, 1996.

[15] L. Albertazzi, "The Wiley Blackwell Handbook of Experimental Phenomenology. Visual Perception of Shape, Space and Appearance," Chichester, Blackwell-Wiley, 2013.

[16] H. De Preester, "Naturalizing Husserlian Phenomenology: An Introduction," Psychoanalytische Perspectieven, vol. 20, no. 4, pp. 633-647, 2002.

[17] G. Fréchette, "Phenomenology as Descriptive Psychology: The Munich Interpretation," Symposium: Canadian Journal of Continental Philosophy, vol. 16, n. 2, pp. 150-170, 2012.

[18] E. Avé-Lallemant, "Die Antithese Freiburg-München in der Geschichte der Phänomenologie," in Die Münchener Phänomenologie. Vortrag des internationalen Kongresses in München 13-18 April 1971, H. Kuhn, E. Avé-Lallemant e R. Gladiator, A cura di, Den Haag, Nijhoff, 1975b, pp. 19-38.

[19] E. Avé-Lallemant, Die Nachlässe der Münchner Phänomenologen in der Bayerischen Staatsbibliothek, Wiesbaden: Harrassowitz, 1975c.

[20] S. Besoli and L. Guidetti, Eds., Il realismo fenomenologico. Sulla filosofia dei Circoli di Monaco e Gottinga," Macerata, Quodlibet, 2000.

[21] D. Moran e R. Parker, Eds., "Early Phenomenology," Studia Phaenomenologica, vol. 15, 2015.

[22] R. Smid, "Münchener Phänomenologie - Zur Frühgeschichte des Begriffs," in Pfänder Studien, H. Spiegelberg and E. AvéLallemant, Eds., Den Haag, Njhoff, 1982, pp. 109-154.

[23] B. Smith, "Realistic Phenomenology," in Encyclopedia of Phenomenology, L. Embree, Ed., Dordrecht, Springer, 1997, pp. 586-590.

[24] G. Fréchette, "Essential Laws: On Ideal Objects and their Properties in Early Phenomenology," in Objects and PseudoObjects: Ontological Deserts and Jungles from Brentano to Carnap, D. Seron, S. Richard e B. Leclercq, A cura di, Berlin, De Gruyter, 2015, pp. 143-166.

[25] A. Peruzzi, "Per un'epistemologia delle matematiche: appunti neo-fenomenologici," in La scienza tra filosofia e storia in Italia nel Novecento, M. Minazzi and L. Zanzi, Eds., Roma, Presidenza del Consiglio dei Ministri, 1987, pp. 521-532.

[26] A. Peruzzi, "Towards a Real Phenomenology of Logic," Husserl Studies, vol. 6, pp. 1-24, 1989.

[27] A. Peruzzi, "Noema fondato," in Fenomenologia applicata, R. Lanfredini, Ed., Milano, Guerini, 2004, pp. 13-38.

[28] A. Peruzzi, "What's Behind Meaning," Philosophical Investigations, vol. 11, n. 21, pp. 119-145, 2017.

[29] A. C. Ehresmann e J. Gomez-Ramirez, "Conciliating Neuroscience and Phenomenology via Category Theory," Progress in Biophysics and Molecular Biology, vol. 119, n. 3, pp. 347-359, 2015.

[30] K. O. Apel, Understanding and Explanation: A Transcendental-Pragmatic Perspective, Cambridge (MA):
MIT Press, 1984.

[31] K. O. Apel, "Metaphysik und die transzendentalphilosophischen Paradigmen der Ersten Philosophie," in Metaphysik. Herausforderungen und Möglichkeiten, V. Hösle, Ed., Stuttgart, Frommann Holzboog, 2002, pp. 1-29.

[32] J. Deely, Four Ages of Understanding. The First Postmodern Survey of Philsophy from Ancient Times to the Turn of the Twenty-First Century, Toronto: University of Toronto Press, 2001.

[33] J. Deely, "Postmodernity as the Unmasking of Objectivity: Identifying the Positive Essence of Postmodernity as a Distinct New Era in the History of Philosophy," Semiotica, vol. 183, n. 1/4, pp. 31-57, 2011.

[34] G. Maddalena, The Philosophy of Gesture. Completing Pragmatists' Incomplete Revolution, Montreal-KingstonLondon-Chicago: McGill-Queen’s University Press, 2015.

[35] A. Ales Bello, The Sense of Things. Toward a Phenomenological Realism (Analecta Husserliana, 118), Cham: Springer, 2015.

[36] M. Scheler, "Vom Wesen der Philosophie und der moralischen Bedingungen des philosophischen Erkennens," in Gesammelte Werke, 2nd a cura di, vol. V, M. Scheu Scheler, A cura di, Bern-München, 1968b, pp. 63-99.

[37] M. Scheler, "Lehre von den drei Tatsachen," in Gesammelte Werke, 3rd ed., vol. X, M. Frings, Ed., Bern-München, Francke, 1986a, pp. 431-474.

[38] M. Scheler, "Probleme der Religion," in Gesammelte Werke, 2nd ed., vol. V, M. Scheu Scheler, Ed., Bern-München, Francke, 1968a, pp. 101-353.

[39] M. Properzi, "L'ontologia formale nella prima fenomenologia di Max Scheler," Dialeghestai, vol 20, https://mondodomani.org/dialegesthai/mpr02.htm, 2018.

[40] S. Besoli, "La svolta in direzione delle cose. Tra le pieghe dell'apriorismo materiale di Scheler," Discipline Filosofiche, vol. XX, n. 2, pp. 183-236, 2010.

[41] M. Scheler, "Zu Wilhelm Jerusalems "Bemerkungen"," in Gesammelte Werke, vol. VI, M. Scheu Scheler, Ed., BernMünchen, Francke, 1963b, pp. 327-331.

[42] M. Scheler, "Der Formalismus in der Ethik und die materiale Wertethik. Neuer Versuch der Grundlegung eines ethischen Personalismus," in Gesammelte Werke, 6 ed., vol. II, M. Scheu Scheler, Ed., Bern-München, Francke, 1980.

[43] M. Scheler, "Phänomenologie und Erkenntnistheorie," in Gesammelte Werke, vol. X, M. Frings, Ed., Bern-München, Francke, 1986b, pp. 377-430.

[44] M. Properzi, "Ontologia formale e teoria della negazione dialettica nella prima fenomenologia di Max Scheler. Un percorso di studio dalla fenomenologia alla Teoria delle Categorie," Acta Philosophica, 2020, in press.

[45] C. S. Peirce, "On the Algebra of Logic," American Journal of Mathematics, vol. 3, pp. 15-57, 1880.

[46] C. S. Peirce, "On the Algebra of Logic: A Contribution to the Philosophy of Notation," American Journal of Mathematics, vol. 7, pp. 180-202, 1885. 
[47] C. S. Peirce, "The Logic of Relatives," The Monist, vol. 7, no. 2, pp. 161-217, 1896.

[48] C. S. Peirce, "Prolegomena to an Apology for Pragmaticism," The Monist, vol. 16, pp. 492-546, 1906.

[49] R. Maddux, "The Origin of Relation Algebras in the Development and Axiomatization of the Calculus of Relations," Studia Logica. An International Journal for Symbolic Logic, vol. 50, no. 3/4, pp. 421-455, 1991.

[50] A. Tarski and S. Givant, A Formalization of Set Theory Without Variables (Colloquium Publications in Mathematics, 41), Providence (RI): American Mathematical Society, 1987.

[51] S. Awodey, Category Theory (Oxford Logic Guides, 49), New York (NY): Oxford University Press, 2006.

[52] A. Rodin, Axiomatic Method and Category Theory (Synthese Library, 364), Cham: Springer, 2014.

[53] S. Abramsky, "Logic and Categories as Tools for Building Theories," Journal of Indian Council of Philosophical Research, vol. 27, pp. 277-304, 2010.

[54] S. Awodey, "Structure in Mathematics and Logic: A Categorical Perspective," Philosophia Mathematica, vol. 4, pp. 209-237, 1996.

[55] S. Awodey, "An Answer to G. Hellman's Question "Does Category Theory Provide a framework for Mathematical Structuralism?"," Philosophia Mathematica, vol. 12, pp. 5464, 2004.

[56] M. Heller, "Category Free Category Theory and its Philosophical Implications," Logic and Logical Philosophy, vol. 25, pp. 447-459, 2016.

[57] J.-P. Marquis, "Category Theory," in The Stanford Encyclopedia of Philosophy, E. N. Zalta, Ed., 2015.

[58] S. Abramsky and N. Tzevelekos, "Introduction to Categories and Categorical Logic," in New Structures for Physics (Lecture Notes in Physics, 813), B. Coecke, Ed., Berlin-New York (NY), Springer, 2011, pp. 3-94.

[59] J. Bell, "From Absolut to Local Mathematics," Synthese, vol. 69, pp. 409-426, 1986.

[60] R. Goldblatt, Topoi: The Categorial Analysis of Logic, Revised ed. ed., Mineola (NY): Dover Publications, 2006.

[61] K. Landsman, Foundations of Quantum Theory. From Classical Concepts to Operator Algebras, Cham: Springer, 2017.

[62] W. Lawvere, "Some Thoughts on the Future of Category Theory," in Proceedings of the International Conference held in Como Italy, July 22-28, 1990, A. Carboni, M. Pedicchio and G. Rosolini, Eds., Berlin, Springer, 1991, pp. 1-13.

[63] W. Lawvere, "Tools for the Advancement of Objective Logic: Closed Categories and Toposes," in The Logical Foundations of Cognition, J. Macnamara and G. Reyes, Eds., Oxford, Oxford University Press, 1994, pp. 43-56.

[64] W. Lawvere, "Unity and Identity of Opposites in Calculus and Physics," Applied Categorical Structures, pp. 167-174, 1996.

[65] B. Mélès, "Pratique mathématique et lecture de Hegel de Jean Cavaillès à William Lawvere," Philosophia Scientiae, vol. 16, pp. 153-182, 2012.
[66] C. Mortensen, Inconsistent Mathematics (Mathematics and Its Applications Series, 312), Dordrecht: Springer, 1995.

[67] R. Angot-Pellissier, "The Relation Between Logic, Set Theory and Topos Theory as it Is Used by Alain Badiou," in The Road to Universal Logic. Festschrift for the 50th Birthday of Jean-Yves Béziau, vol. II, A. Koslow and A. Buchsbaum, Eds., Cham, Springer, 2015, pp. 181-200.

[68] L. Estrada-Gonzàles, "The Evil Twin: The Basics of Complement-Toposes," in New Directions in Paraconsistent Logic (Proceedings in Mathematics \& Statistics, 152), J. Bèziau, M. Chakraborty and S. Dutta, Eds., New Delhi, Springer, 2015, pp. 375-425.

[69] L. Estrada-Gonzàles, "Complement-Topoi and Dual Intuitionistic Logic," Australasian Journal of Logic, vol. 9, pp. 26-44, 2010.

[70] W. Lawvere, "Quantifiers and Sheaves," in Actes du Congrès International des Mathématiciens (Nice, 1970), vol. I, Paris, 1971, pp. 329-334.

[71] F. Kruse, "Genuineness and Degeneracy in Peirce's Categories," Transactions of the Charles S. Peirce's Society. A Quarterly Journal in American Philosophy, vol. 27, pp. 267298, 1991.

[72] J. Deely, "Semiosis and 'meaning as use': The indispensability and insufficiency of subjectivity in the action of signs," Sign System Studies, vol. 43, no. 1, pp. 7-28, 2015.

[73] J. Ransdell, "Peirce est-il un phénoménologue?" Ètudes Phénoménologiques, vol. 9, no. 10, pp. 51-75, 1989.

[74] A. De Tienne, "Is Phaneroscopy as a Pre-Semiotic Science Possible?" Semiotiche, vol. 2, pp. 15-30, 2004.

[75] G. Fuhrman, "Peirce's Retrospectives on his Phenomenological Quest," Transactions of the Charles S. Peirce Society: A Quarterly Journal in American Philosophy, vol. 49, no. 4, pp. 490-508, 2013.

[76] G. Sonesson, "Phenomenology meets Semiotics: Two Not So Very Strange Bedfellows at the End of their Cinderella Sleep," Metodo. International Studies in Phenomenology and Philosophy, vol. 3, no. 1, pp. 41-62, 2015.

[77] S. Luft, "Husserl's Theory of the Phenomenological Reduction: Between Life-World and Cartesianism," Research in Phenomenology, vol. 34, pp. 198-234, 2004.

[78] W. Hartmann, Max Scheler. Bibliographie, Stuttgart: Frommann, 1963.

[79] M. Scheler, "Die Idole der Selbsterkenntis," in Gesammelte Werke, vol. III, M. Scheu Scheler, Ed., Bern-München, Francke, 1955, pp. 213-292..

[80] D. Moran, Edmund Husserl. Founder of Phenomenology, Cambridge: Polity, 2005.

[81] S. Centrone and J. Da Silva, "Husserl and Leibniz: Notes on the Mathesis Universalis," in n: S. Centrone Essays on Husserl's Logic and Philosophy of Mathematics (Synthese Library, 384), S. Centrone, Ed., Dordrecht, Springer, 2017, pp. 1-24.

[82] D. Verducci, "L'analogia depotenziata. Ovvero: elementi di metafisica fenomenologica nella filosofia di Max Scheler," in Studi di filosofia trascendentale, V. Melchiorre, Ed., Milano, Vita e Pensiero, 1993, pp. 215-258. 
[83] M. Scheler, "Reine Tatsache und Kausalbeziehung (Phänomenologie und Kausalerklärung)," in Gesammelte Werke, 3rd ed., vol. X, M. Frings, Ed., Bern-München, Francke, 1986c, pp. 475-492.

[84] M. Scheler, "Weltanschauungslehre, Soziologie und Weltanschauungssetzung," in Gesammelte Werke, vol. VI, M. Scheu Scheler, Ed., Bern-München, Francke, 1963a, pp. 1326.

[85] A. Rodin, "Categorical Model Theory and the Semantic View of Theories," 2016.

[86] T. Borsche, "Denken - Sprache - Wirklichkeit. Grundlinien der Sprachphilosophie Wilhelm von Humboldts," in Menschheit und Individualität, E. Wicke, W. Neuser and W. Schmied-Kowarzik, Eds., Weinheim, Deutsche Studien, 1997, pp. 65-81.

[87] E. Avé-Lallemant, "Bio-Bibliographischer Anhang," in Max Scheler in gegenwartgeschehen der Philosophie, P. Good, Ed., Bern-München, Francke, 1975a, pp. 267-284.
[88] V. Biceaga, The Concept of Passivity in Husserl's Phenomenology, Dordrecht: Springer, 2010.

[89] M. Properzi, "Il giovane Scheler e l'epistemologia," Dialegesthai. Rivista telematica di filosofia, vol. 20, https://mondodomani.org/dialegesthai/mpr01.htm, 2018.

[90] M. D. Barber, Guardian of Dialogue: Max Scheler's Phenomenology, Sociology of Knowledge, and Philosophy of Love, London - Toronto: Bucknell University Press, 1993.

[91] M. Properzi, "Materia e forma nella prima estetica fenomenologica di Max Scheler," Rivista Internazionale di Filosofia e Psicologia, vol. 9, n. 2, pp. 162-177, 2018.

[92] J.-Y. Béziau, "The Future of Paraconsistent Logic," Logical Studies, vol. 2, pp. 1-17, 1999.

[93] J.-Y. Béziau, "Paraconsistent Logic from a Modal Viewpoint," Journal of Applied Logic, vol. 3, pp. 7-14, 2005. 